\title{
Tsunami ECHO Team Response
}

\author{
Dr. Hugh Grantham
}

ECHO Team Leader

Correspondence:

Dr. Hugh Grantham

South Australia Ambulance Service GPO Box 3

Adeleide SA 5001

Australia

E-mail:

grantham.hugh@saambulance.com.au

Web publication: 12 October 2006

\section{Dear Editor:}

The ECHO Team was the second Australian team to arrive to Banda Aceh, Indonesia in response to the Southeast Asia Earthquake and Tsunami. The ECHO Team continued the work of the first Australian Team which consisted of members of the Alpha and Bravo Teams. The ECHO team left Australia on 08 January 2005. The following describes some of the more significant logistical challenges encountered by the ECHO Team. The issues the ECHO Team confronted were those expected during a mission to help to manage a disaster.

The major clinical challenge faced was performing clinical tasks to the highest standard despite infrastructure failure typified by a lack of power, water, and supply lines.

When compared with the experience obtained from other events, the major, noteworthy component of this response was the extent of the international community's involvement and cooperation in the field.

Initially, the Team had planned to fly via Darwin to Medan, and then by military Hercules Aircraft from Medan to Banda Aceh. The first attempt to reach Medan resulted in a diversion of the aircraft to Batam, just south of Singapore. The next day, the Team was diverted to Kuala Lumpur. This experience presented the Team with a challenge because the Team was on a nonscheduled plane, with a substantial amount of pharmaceuticals on-board, in the wrong country, without clearance. After three hours on the tarmac, the Team was allowed to fly to Penang, and traveled by land to Butterworth, where they stayed at a Malaysian military airfield within an Australian Hercules base. Once again, the Team was in the wrong country with the pharmaceutical cargo, but this time they were on a military air base belonging to another country. During the pre-dawn hours of the third day, the Team was flown to Banda Aceh by Hercules.

Starting a day exhausted, sleep deprived, and landing in a strange environment before dawn is not optimal in terms of team welfare. Moving ten tons of equipment in a high humidity environment by members of a medical team who were not accustomed to this level of physical activity presented an additional possible hazard to carrying out the mission. An example of the extra precautions needed to safeguard the functionality of medical personnel was the use of rigging gloves to protect hands from injury.

The town was damaged significantly by the Earthquake. Electrical power was intermittent, and adequate supplies of potable water presented a considerable logistical challenge. The lack of adequate supplies of water made using functional toilets a challenge. Water had to be carried from a pump located near a swamp, which was next to the hospital. The intricacies of the arrangement were self-evident. The situation worsened when some Team members succumbed to a vicious bout of diarrhea.

The Tsunami devastated the area on an astounding scale, and some of the Team members commented on what Hiroshima must have looked like after the atomic blast. Two weeks after the event, the extent of the destruction and the number of unburied dead was distressing. Tropical temperatures and frequent monsoonal rains hampered the clean-up. 
Repeated requests by Team members for access to fax or e-mail were frustrated by an environment in which voice communication using mobile phone was patchy, and the only modality that worked was a short message service. Even the use of satellite phones was unreliable.

Most of the survivors of the Earthquake and Tsunami were young, and the majority had sustained injuries to their lower limbs. Those with other types of injuries stood little chance of survival.

The ECHO Team performed 130 operations without adequate supplies of water, and with intermittent electrical power. Despite these problems, results from plastic reconstruction surgery were excellent-all of the flaps took. The injured victims were of varying ages, however, there was an absence of children even though they comprised nearly one-third of the population.

A cultural issue that was encountered was the belief that only the "perfect go to heaven". When a patient is confronting an amputation, this deficit becomes a significant issue. Team members and an interpreter guided the actions of the ECHO Team in this respect.

The prevalence of anemia in many of the victims further complicated the clinical challenges. One patient required multiple trips to the surgical theater and with a hemoglobin concentration of $3 \mathrm{gm} / \mathrm{dl}$ without any oxygen available. A two-unit transfusion of fresh blood was completed by using local donors.

Aspiration pneumonia was a severe problem, and caused the deaths of many young people. The principal pathogen identified was a soil-based Nocardia. X-rays only were obtained after forcibly opening the $x$-ray room, and with the assistance of one of the surviving local technicians.

Unfortunately, tetanus cases were plentiful, and reflected a failure of preventive medicine in the past. Initially, the mortality was $100 \%$, but this was improved by establishing a specific tetanus unit. At its peak, there were 60-90 known cases of tetanus in the region.

Multiple agencies and nationalities converged to provide aid and provided unique opportunities for collaboration, but also provided abundant opportunities for duplication and confusion.

While many Team members had experience at a local response level, and a few had experience at a single nation response level to a disaster, there was very little experience available at the multinational, coordinated response level. The issues and lessons associated with coordinating an effective, multinational response included language and cultural barriers, a lack of a common command structure, and dislocation between the support/supply structures for the individual national and/or organizational teams. The impact of the complexity of management issues upon pro- viding a coordinated, multinational response was apparent in Banda Aceh. This issue must be addressed specifically for multinational operations as part of disaster management training for teams and support coordinators in the field. This level of complexity of the management issues must be appreciated. This issue must be addressed specifically for multinational operations as a part of disaster-management training for teams as well as support coordinators in the field.

In the hospital, the members of the ECHO Team were responsible for supervising a team comprised of professionals from six nations. To add to the complexity of the situation, the membership of the team changed as the mission progressed. Achieving consensus and a team effort with language and cultural barriers was a challenge, but was achieved within 48 hours.

The ECHO Team also contributed to the overall coordination of the international effort on behalf of the World Health Organization (WHO). Although useful, it was not a role that was anticipated. The WHO had achieved coordination and cooperation and established an effective public health surveillance system. Additional challenges included new teams that arrived unannounced with no clearly designated mission. For example, a 150-strong field medical team from the Russian army arrived without notice.

Hazards to the health and safety of the ECHO team included: (1) continued gunfire/warfare in the affected area; (2) repeated aftershocks that threatened to collapse already weakened buildings; and (3) health risks to the Team members, including pneumonia, severe diarrhea, and worms. Transportation also was hazardous, as demonstrated by helicopter crashes and the lack of traffic rules and adequate road surfaces.

Departing Banda Aceh also was eventful, as the Hercules aircraft used developed a pressurization problem that required an emergency landing and precipitated health problems in some of the Team members.

The lessons learned from this mission include: (1) the value of teamwork and a dynamic team structure that enabled the Team members to cope with minor problems; and (2) the lateral thinking and improvization required to meet the logistical challenges.

Despite the need for adequate communication being emphasized at every briefing before the mission began, communiucation failure was an important issue in this situation. Solutions to improve communication include: (1) the use of and practice of an alternative system (satellite phone); and (2) a realization by those with support roles that communication will be difficult. The multinational nature of this disaster, and the specific issues brought up by the multinational response probably were the most significant issues of the mission. 